
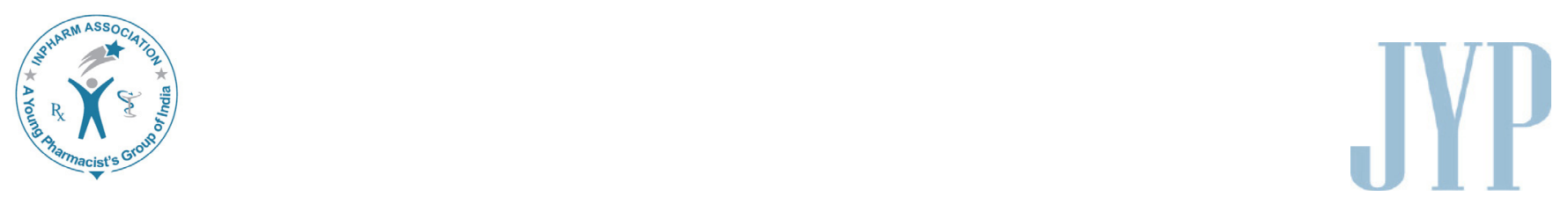

\title{
Clinical Evaluation of Retention in Hydrophobic and Hydrophillic Pit and Fissure Sealants-A Two Year Follow-Up Study
}

\author{
Akurathi Ratnaditya', Mallela George Manoj Kumar², Sai Sankar Avula \\ Jogendra ${ }^{3}$, Mohammad Zabirunnisa ${ }^{4}$, Chaitanya Ram Kandregula ${ }^{5}$, Raj \\ Kumar chowdhary Kopuri ${ }^{6}$
}

${ }^{I}$ Department of Pedodontics, Vishnu Dental College, Bhimavaram, AP, INDIA

${ }^{2}$ Department of Pedodontics, SVS institute of Dental Sciences, Mehboobnagar, Telangana, INDIA

${ }^{3}$ Department of Pedodontics and Preventive Dentistry, Sibar Institute of Dental Sciences, Guntur, AP, INDIA

${ }^{4}$ Department of Public Health Dentistry, Vishnu Dental College, Bhimavaram, AP, INDIA

${ }^{5}$ Department of Pedodontics, Drs Sudha \& Nageswara Rao Siddhartha Institute of Dental Sciences,

Chinaoutpalli, AP, INDIA

${ }^{6}$ Department. of Pedodontics, St. Joseph Dental College, Eluru AP, INDIA

\section{ABSTRACT}

Objectives: The present in vivo study is done to compare and evaluate the retention of the traditional hydrophobic pit and fissure sealant with a hydrophilic resin-based sealant on first permanent molars and to compare the sealant retention in maxillary and mandibular first permanent molars. Materials and Methods: In this randomized clinical trial 212 permanent first molars from 76 subjects are considered in this study. Out of which 106 right side upper \& lower first molars were sealed with Delton FS (Group I) and the remaining 106 left side upper \& lower first molars were sealed with Embrace Wet Bond sealant (Group II). Clinical evaluation by both visual and tactile examination was carried out -immediately after sealant application, at 1,6,12,18 and 24 months using Simonsen's criteria. Results: At the end of two years $67.9 \%$ of permanent molars of group II showed completely retained sealants compared to $45.3 \%$ of permanent molars of group I. Conspicuously $56.6 \%$ upper teeth in group II retained sealant, whereas only $17 \%$ of upper teeth retained sealant in group I and is statistically significant $(p=0.01)$. Conclusion: It can be concluded that hydrophilic sealant may be used as effective pit and fissure sealants especially in children with high risk of caries, excessive salivation, mentally and physically challenged, very young children, uncooperative child and partially erupted molars and community care programs.

Key words: Children Dentistry, First permanent molars, Hydrophobic sealants, Hydrophillic sealants, Pits and Fissures, Retention.

\begin{tabular}{|c|c|}
\hline \multicolumn{2}{|c|}{ Access this article online } \\
\hline Journal Sponsor & \multirow[b]{2}{*}{$\begin{array}{l}\text { Website: } \\
\text { www.jyoungpharm.org }\end{array}$} \\
\hline \multirow{2}{*}{ www.phcog net } & \\
\hline & $\begin{array}{l}\text { DOI: } \\
\text { 10.5530/jyp.2015.3.6 }\end{array}$ \\
\hline
\end{tabular}

\section{INTRODUCTION}

Pits and fissures are considered as the single most important feature leading to development of occlusal caries. ${ }^{1}$ The complex morphology of occlusal pits and fissures make them an ideal site for retention of bacteria and food remnants rendering the performance of proper hygiene

*Address for correspondence:

Dr. Akurathi Ratnaditya, Assistant Professor, Department of Pedodontics, Vishnu Dental College, Bhimavaram-534202, AP, INDIA.

E-mail :dradityahok@gmail.com 


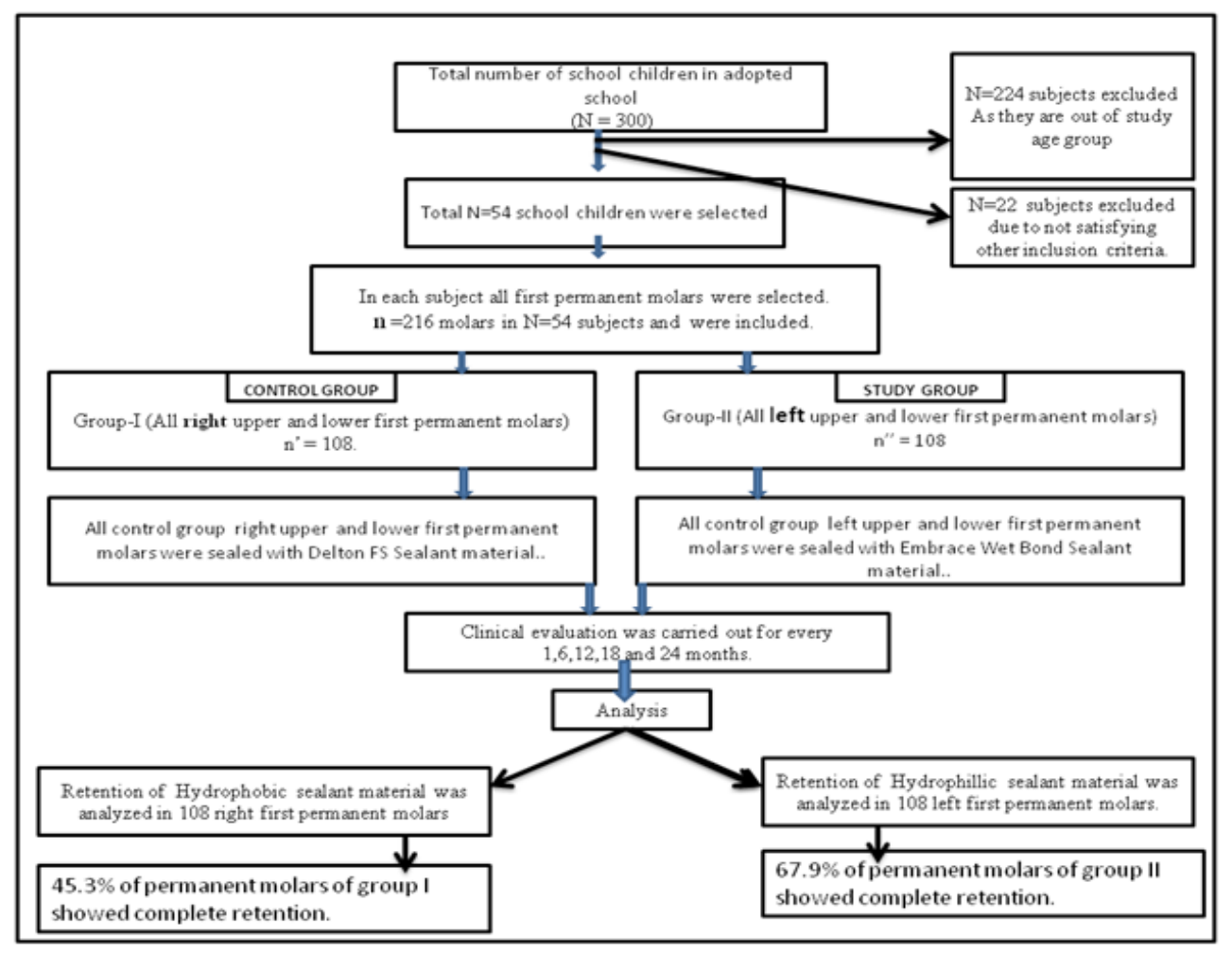

Graphical Abstract

difficult or even impossible. ${ }^{2}$ Another factor responsible for the high incidence of occlusal caries is the lack of salivary access to the fissures as a result of surface tension, effectively preventing remineralisation and reducing the effectiveness of Fluoride. ${ }^{3}$

Pit and fissure sealants have been shown to be extremely effective in preventing occlusal caries, and there is considerable research documenting sealant success over extended periods. ${ }^{2,47}$ The primary measure of sealant efficacy is retention. The clinical efficacy of fissure sealants is directly related to their retention. ${ }^{6-9}$ If the sealant material stays bonded to the tooth and provides a good seal, then it is reasonable to expect that caries incidence can be decreased. ${ }^{\text {? }}$

Traditional pit and fissure sealants are hydrophobic and cannot be applied where there is moisture to ensure success. ${ }^{9-11}$ So isolation is mandatory for traditional sealants, but is extremely difficult with erupting teeth. ${ }^{9}$ These materials are based non bis-GMA and other monomers that are primarily hydrophobic in nature and require a dry field. Many authors recommend their use with hydrophilic bonding agents as a way to overcome the dry field requirement. However, the bonding agents add considerable time and cost to the procedure, and the procedure becomes more technique sensitive. ${ }^{12,13}$
In recent years resin-based sealant technology has been developed that incorporates a moisture-tolerant resin chemistry and behaves favourably in the moist oral environment. ${ }^{8}$ This study was taken up to compare the retention of traditional hydrophobic pit and fissure sealant with a hydrophilic resin-based sealant on first permanent molars and to compare the sealant retention in maxillary and mandibular first permanent molars.

\section{MATERIAL AND METHODS}

A total of 300 subjects aged between 6-9 years were screened in the Department of Pedodontics and Preventive Dentistry, among which 76 healthy cooperative children with all four newly erupted caries free and untreated permanent first molars were selected for inclusion in this study, with written parent consent. The inclusion criteria specified that the occlusal surfaces had to be fully visible and free of mucosal tissue. The children with hypoplastic permanent first molars, developmental anomalies were excluded from the study. Twenty three children who did not turn up with consent form and for regular follow up were excluded from the study.

Ethical clearance to conduct the study was obtained from the institutional review board. Fifty three children with 212 
permanent first molars in all 4 quadrants were considered for this study. Out of which 106 right side upper \& lower first molars [i.e. 16 \& 46] were sealed with Group-I (Group I) and the remaining 106 left side upper \& lower first molars [i.e.26 \& 36] were sealed with Group-II sealant (Group II).

A single operator carried out oral prophylactic procedures for the teeth to be restored by using slurry of pumice and a rotating brush to ensure removal of debris from the fissures. The occlusal surface is thoroughly flushed with water to remove any remnants. Isolation is achieved by using cotton rolls and a saliva ejector held by an assistant. 37\% Ortho Phosphoric acid etchant gel was applied with a disposable nylon applicator tip on to the pit and fissures, extended up the cuspal inclines. Each tooth was etched up to 20 seconds and rinsed for 30 seconds using an air-water syringe.

In Group I samples $(16,46)$ the etched surface is thoroughly dried till 'matte frosty white' appearance is seen, followed by the application of hydrophobic pit and fissure sealant (Delton FS) on the tooth surfaces using disposable applicator tips. A probe was used to remove the entrapment of air bubbles and to ensure that the sealant flows into all the pits and fissures. Material was cured using visible light for 20 seconds (according to the manufacturer's instructions) and checked for the hardening of the material using an explorer. ${ }^{5}$

In Group II samples (26 36), the etched surface is dried with cotton pellets and moisture is left with a glossy appearance and proceeded with the application of hydrophilic pit and fissure sealant (Group-II). In case of salivary contamination, the surface is cleaned, dried and re-etched. Inspection of sealant was done for complete coverage or voids. The patients were instructed not to eat or drink anything for 30 minutes. Clinical evaluation by both visual and tactile examination was carried out with recalls at intervals of 1, 6, 12, 18 and 24 months for assessment of sealant retention. Intra-examiner variability was minimized by re-examining $10 \%$ of patients. Retention of the sealants at the specified time intervals was evaluated using Simenson's criteria. ${ }^{5}$ The data obtained was tabulated and subjected to statistical analysis using Chi-square test and $\mathrm{Z}$ test.

\section{RESULTS}

\section{Comparison of retention of the two sealants}

On comparison, both materials were found to be effective as pit and fissure sealants with varying degree of success in terms of retention (Table 1 and Figure 1).

\section{Evaluation at first month}

Out of 106 teeth in group-I (Delton FS), 98 teeth (92.45\%) showed complete retention of sealant, as compared to 99 teeth $(93.40 \%)$ of group-II (Group-II sealant). The difference in the degree of retention between the two sealants was not statistically significant.

\section{Evaluation at Six months}

Eighty-one teeth $(76.4 \%)$ of Group-I sealant was completely retained when compared to ninety-three teeth $(87.7 \%)$ of group-II. This difference was statistically significant. Partial sealant retention was seen in eleven teeth $(10.4 \%)$ sealed with group-I sealant as compared to eight teeth $(7.5 \%)$ sealed with group-II sealant. Only five teeth $(4.7 \%)$ showed missing sealant in group-II compared to thirteen teeth $(12.3 \%)$ group-I and the difference was found statistically significant.

\section{Evaluation at twelve months}

A $59.4 \%$ of Group-I sealant (63 teeth) were completely retained as compared to $82.1 \%$ (93 teeth) of Group-II which was found highly significant $(p=0.00)$. Sixteen teeth $(15.1 \%)$ of Group-I were partially retained, while nine teeth $(8.5 \%)$ of Group-II. Twenty four teeth $(22.6 \%)$ lost sealant in Group-I and 10 teeth (9.4\%) in Group-II which was found statistically significant $(p=0.008)$.

\section{Evaluation at eighteen months}

A 50.9\% (54 teeth) of Group-I sealant showed complete retention of sealant compared to 84 teeth $(79.2 \%)$ of Group-II which was found highly significant $(p=0.00)$. Eighteen teeth $(17.0 \%)$ of Group-I sealant was partially retained when compared to 9 teeth $(8.5 \%)$ of Group-II. Thirty of the Group-I sealed teeth $(28.3 \%)$ and twelve of the Group-II sealed teeth (11.3\%) showed missing sealants which was statistically significant $(p=0.002)$.

\section{Evaluation at Twenty-four months}

Group-I sealant was completely retained in eighty-one teeth (76.4\%) when compared to ninety-three teeth $(87.7 \%)$ of Group-II sealant. This difference was statistically significant $(p=0.001)$. Partial sealant retention was seen in eleven teeth $(10.4 \%)$ sealed with Group-I sealant as compared to eight teeth $(7.5 \%)$ sealed with Group-II sealant. Thirteen teeth $(12.3 \%)$ showed missing Group-I sealant and five teeth (4.7\%) showed missing Group-II sealant, the difference was found statistically significant. Consistency of statistical 


\begin{tabular}{|c|c|c|c|c|c|c|c|}
\hline \multirow{2}{*}{ Evaluation } & \multirow{2}{*}{ Retention } & \multicolumn{2}{|c|}{$\begin{array}{l}\text { Delton FS pit \& fissure } \\
\qquad(n=106)\end{array}$} & \multicolumn{2}{|c|}{$\begin{array}{l}\text { Embrace WET } \\
\text { bond }(n=106)\end{array}$} & \multicolumn{2}{|c|}{ Significance } \\
\hline & & & & Number & $\%$ & $Z$ value & P-value \\
\hline \multirow{4}{*}{1 month } & C & 98 & 92.5 & 99 & 93.4 & -0.27 & 0.79 \\
\hline & $P$ & 6 & 5.7 & 4 & 3.8 & 0.65 & 0.52 \\
\hline & M & 2 & 1.9 & 3 & 2.8 & -0.45 & 0.65 \\
\hline & $\mathrm{D}$ & 0 & 0.0 & 0 & 0.0 & 0.00 & 1.00 \\
\hline \multirow{4}{*}{6 months } & C & 81 & 76.4 & 93 & 87.7 & -2.17 & $0.03^{*}$ \\
\hline & $\mathrm{P}$ & 11 & 10.4 & 8 & 7.5 & 0.72 & 0.47 \\
\hline & M & 13 & 12.3 & 5 & 4.7 & 1.99 & $0.04^{*}$ \\
\hline & D & 1 & 0.9 & 0 & 0.0 & 1.00 & 0.32 \\
\hline \multirow{4}{*}{12 months } & C & 63 & 59.4 & 87 & 82.1 & -3.74 & $0.00^{* *}$ \\
\hline & $\mathrm{P}$ & 16 & 15.1 & 9 & 8.5 & 1.50 & 0.13 \\
\hline & M & 24 & 22.6 & 10 & 9.4 & 2.66 & $0.008^{*}$ \\
\hline & $D$ & 3 & 2.8 & 0 & 0.0 & 1.76 & 0.08 \\
\hline \multirow{4}{*}{18 months } & C & 54 & 50.9 & 84 & 79.2 & -4.53 & $0.00^{* *}$ \\
\hline & $P$ & 18 & 17.0 & 9 & 8.5 & 1.87 & 0.06 \\
\hline & M & 30 & 28.3 & 12 & 11.3 & 3.17 & $0.002^{*}$ \\
\hline & D & 4 & 3.8 & 1 & 0.9 & 1.36 & 0.17 \\
\hline \multirow{4}{*}{24 months } & C & 48 & 45.3 & 72 & 67.9 & -3.42 & $.001^{*}$ \\
\hline & $P$ & 18 & 17.0 & 12 & 11.3 & 1.19 & 0.23 \\
\hline & $M$ & 36 & 34.0 & 21 & 19.8 & 2.35 & $0.02^{*}$ \\
\hline & $\mathrm{D}$ & 4 & 3.8 & 1 & 0.9 & 1.36 & 0.17 \\
\hline
\end{tabular}

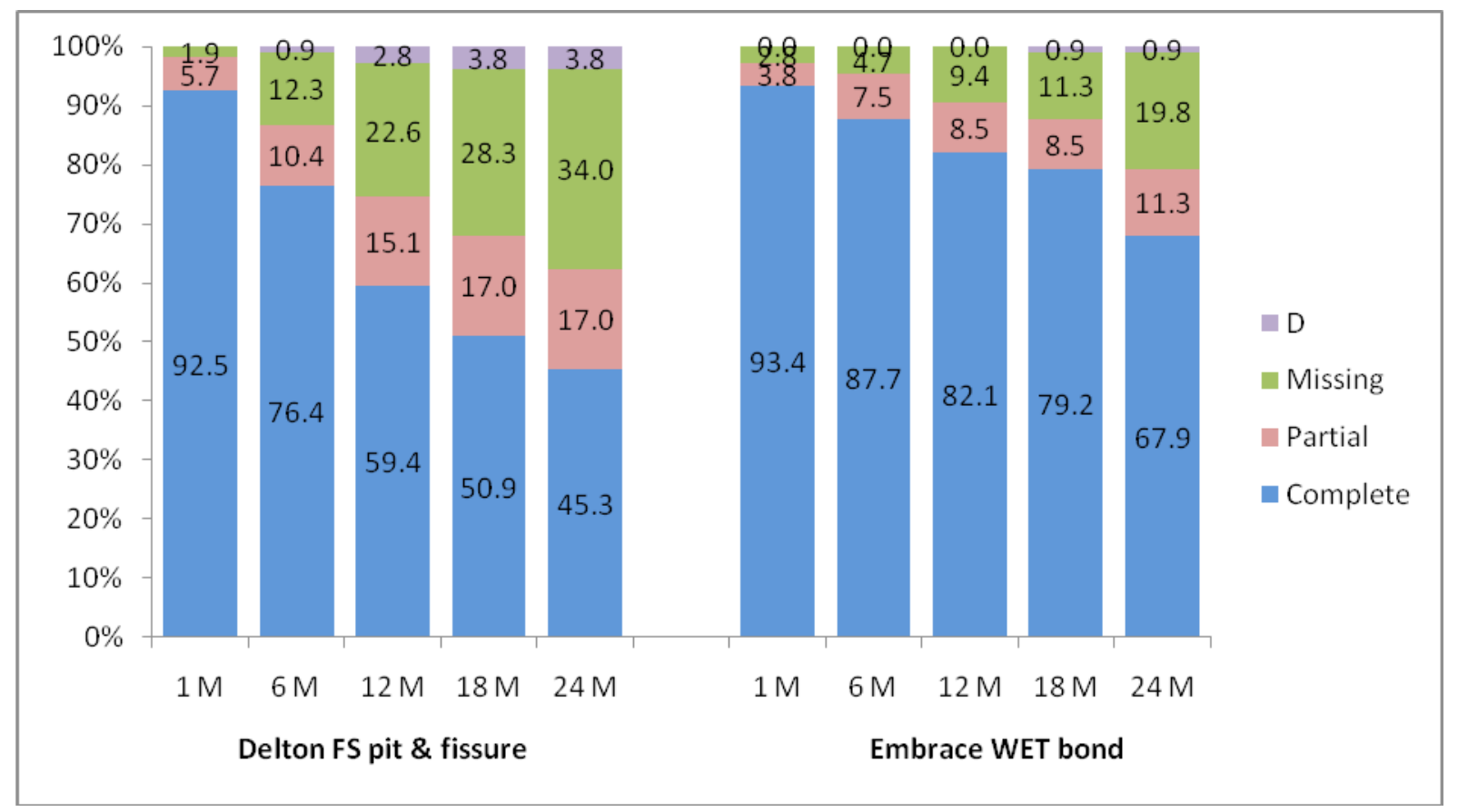

Figure 1: Comparison of sealant Retention of Hydrophilic And Hydrophobic Sealant 
significance was observed at the end of $6,12,18,24$ months with high statistical significance in twelve and eighteen months.

\section{Comparison of sealant retention on upper and lower first permanent molars}

\section{Evaluation at first month}

In Group-I Forty eight upper teeth (90.6\%) shown complete retention of sealant as compared to 50 lower teeth (94.3\%). Where as in Group-II 92.5\% of sealant (49 teeth) was completely retained on upper teeth as compared to $94.3 \%$ (50 teeth) on lower teeth (Table 2 and Figure 2).

\section{Evaluation at six months}

A $64.2 \%$ of Group-I sealant (34 teeth) was completely retained on upper teeth as compared to $88.7 \%$ of sealant (47 teeth) on lower teeth which was found statistically significant $(p=0.002)$ This Sealant was partially retained on 8 upper teeth (15.1\%) and on 3 lower teeth (5.7\%). The sealant was missing on 10 upper teeth (18.9\%), 3 lower teeth $(5.7 \%)$ and was found statistically significant $(p=0.003)$. Where as in Group-II 83.0\% (44 teeth) was completely retained on upper teeth as compared to 49 teeth $(92.5 \%)$ on lower teeth. The sealant was partially retained on 5 upper teeth (9.4\%) and on 3 lower teeth (5.7\%). Four teeth $(7.5 \%)$ of upper teeth and $1.9 \%$ of lower teeth (1 teeth) showed missing sealant.

\section{Evaluation at twelve months}

In Group-I sealant, 17 upper teeth $(32.1 \%)$ showed complete sealant retention as compared to 46 lower teeth $(86.8 \%)$. which was found highly significant $(p=0.00)$ The sealant was partially retained on 14 upper teeth $(26.4 \%)$ and on 2 lower teeth (3.8\%). twenty teeth (37.7) of upper teeth and $7.5 \%$ (4 teeth) of lower teeth showed missing sealant which was also highly significant $(p=0.00)$. Where as in Group-II, 40 teeth (75.5\%) sealant was completely retained on upper teeth as compared to $88.7 \%$ of sealant (47 teeth) on lower teeth. Seven teeth $(13.2 \%)$ of partial retention were seen in upper teeth where as $3.8 \%$ on 2 lower teeth. The sealant was missing from 6 upper teeth $(11.3 \%)$ and 4 lower teeth $(7.5 \%)$.

\section{Evaluation at eighteen months}

In Group-I High statistical significance was found in complete, partial and loss of sealant. 12 upper teeth $(22.6 \%)$ showed complete sealant retention as compared to 42 lower teeth $(79.2 \%)(p=0.00)$. The sealant was partially retained on 15 upper teeth $(28.3 \%)$ and on 3 lower teeth $(5.7 \%)(p=0.001)$. Twenty-four $(45.3 \%)$ of upper teeth and $11.3 \%$ (6 teeth) $(p=0.00)$ of lower teeth showed missing sealant. Where as in Group-II, 38 teeth (71.7\%) sealant was completely retained on upper teeth as compared to $86.8 \%$ of sealant (46 teeth) on lower teeth. Seven teeth $(13.2 \%)$ of partial retention was seen in upper teeth where as 3.8\% on 2 lower teeth. The sealant was missing from 8 upper teeth $(15.1 \%)$ and 4 lower teeth $(7.5 \%)$.

\section{Evaluation at twenty four months}

In Group-I High statistical significance was found in complete, partial and loss of sealant. Nine upper teeth $(17 \%)$ showed complete sealant retention as compared to 39 lower teeth $(73.6 \%)(p=0.00)$. The sealant was partially retained on 15 upper teeth $(28.3 \%)$ and on 3 lower teeth $(5.7 \%)(p=0.001)$. Twenty-seven teeth $(50.9 \%)$ of upper teeth and $17 \%$ (9 teeth) ( $p=0.00$ ) of lower teeth showed missing sealant. Where as in Group-II, 30 teeth (71.7\%) sealant was completely retained on upper teeth as compared to $79.2 \%$ of sealant (42 teeth) on lower teeth. nine teeth $(17 \%)$ of partial retention was seen in upper teeth where as $5,7 \%$ on 3 lower teeth. The sealant was missing from 14 upper teeth (26.4\%) and 7 lower teeth (13.2\%).

Consistency of statistical significance was observed in Group I at the end of 12,18,24 months which shows the efficacy of retention in Group II upper quadrant sealants.

\section{DISCUSSION}

Fissure sealants are mainly considered to be highly effective in prevention of pit and fissure caries. ${ }^{15}$ The caries-prevention property of sealants depends on the establishment of a seal which prevents nutrients from reaching the microflora in the pits and fissures. Pit and fissures are approximately eight times vulnerable than the smooth surfaces. ${ }^{10}$ Therefore there lies the importance of placement and retention of sealant is crucial. The sealants which are commercially available are Hydrophobic resin based sealants, very technique-sensitive and are influenced by several factors, such as Patient co-operation, Operator variability and Contamination of the operating field. ${ }^{11,12}$ A major drawback of sealing fissures is that the clinical procedure is extremely sensitive to moisture, which makes it difficult to etch partially erupted molars. ${ }^{13}$

This present study evaluated the retention of Resin based sealants, Group-I which is fluoride releasing and has long positive clinical use since 20 years with "Embrace "WM Wet Bond" ${ }^{\text {TM" }}$ which is one of the recent advances 
Table 2: Comparison of sealant retention on upper and lower first permanent molars

\begin{tabular}{|c|c|c|c|c|c|c|c|c|c|c|c|c|c|}
\hline \multirow{2}{*}{ Evaluation } & \multirow{2}{*}{ Retention } & \multicolumn{4}{|c|}{$\begin{array}{l}\text { Delton FS Sealant } \\
\qquad(n=106)\end{array}$} & \multirow{2}{*}{ Z-value } & \multirow{2}{*}{ P-value } & \multicolumn{4}{|c|}{$\begin{array}{l}\text { Embrace Wet Bond Sealant } \\
\qquad(n=106)\end{array}$} & \multirow{2}{*}{ Z-value } & \multirow{2}{*}{ P-value } \\
\hline & & $\begin{array}{l}\text { Upper } \\
(n=53)\end{array}$ & $\%$ & $\begin{array}{l}\text { Lower } \\
(n=53)\end{array}$ & $\%$ & & & $\begin{array}{l}\text { Upper } \\
(n=53)\end{array}$ & $\%$ & $\begin{array}{l}\text { Lower } \\
(n=53)\end{array}$ & $\%$ & & \\
\hline \multirow{4}{*}{1 month } & C & 48 & 90.6 & 50 & 94.3 & -0.74 & 0.46 & 49 & 92.5 & 50 & 94.3 & -0.39 & 0.70 \\
\hline & $\mathrm{P}$ & 4 & 7.5 & 2 & 3.8 & 0.84 & 0.40 & 2 & 3.8 & 2 & 3.8 & 0.00 & 1.00 \\
\hline & $M$ & 1 & 1.9 & 1 & 1.9 & 0.00 & 1.00 & 2 & 3.8 & 1 & 1.9 & 0.59 & 0.56 \\
\hline & $\mathrm{D}$ & 0 & 0.0 & 0 & 0.0 & 0.00 & 1.00 & 0 & 0.0 & 0 & 0.0 & 0.00 & 1.00 \\
\hline \multirow{4}{*}{6 months } & C & 34 & 64.2 & 47 & 88.7 & -3.11 & $0.002^{*}$ & 44 & 83.0 & 49 & 92.5 & -1.50 & 0.13 \\
\hline & $\mathrm{P}$ & 8 & 15.1 & 3 & 5.7 & 1.61 & 0.11 & 5 & 9.4 & 3 & 5.7 & 0.74 & 0.46 \\
\hline & M & 10 & 18.9 & 3 & 5.7 & 2.12 & $0.03^{*}$ & 4 & 7.5 & 1 & 1.9 & 1.39 & 0.17 \\
\hline & $\mathrm{D}$ & 1 & 1.9 & 0 & 0.0 & 1.01 & 0.31 & 0 & 0.0 & 0 & 0.0 & 0.00 & 1.00 \\
\hline \multirow{4}{*}{12 months } & C & 17 & 32.1 & 46 & 86.8 & -6.91 & $0.00^{\star \star}$ & 40 & 75.5 & 47 & 88.7 & -1.80 & 0.07 \\
\hline & $\mathrm{P}$ & 14 & 26.4 & 2 & 3.8 & 3.43 & $0.001^{*}$ & 7 & 13.2 & 2 & 3.8 & 1.77 & 0.08 \\
\hline & $M$ & 20 & 37.7 & 4 & 7.5 & 3.98 & $0.00^{\star \star}$ & 6 & 11.3 & 4 & 1.9 & 0.67 & 0.50 \\
\hline & $\mathrm{D}$ & 2 & 3.8 & 1 & 1.9 & 0.59 & 0.56 & 0 & 0.0 & 0 & 0.0 & 0.00 & 1.00 \\
\hline \multirow{4}{*}{18 months } & C & 12 & 22.6 & 42 & 79.2 & -7.07 & $0.00^{\star \star}$ & 38 & 71.7 & 46 & 86.8 & -1.95 & $0.05^{\star}$ \\
\hline & $\mathrm{P}$ & 15 & 28.3 & 3 & 5.7 & 3.26 & $0.001^{*}$ & 7 & 13.2 & 2 & 3.8 & 1.77 & 0.08 \\
\hline & M & 24 & 45.3 & 6 & 11.3 & 4.19 & $0.00^{\star \star}$ & 8 & 15.1 & 4 & 7.5 & 1.23 & 0.22 \\
\hline & D & 2 & 3.8 & 2 & 3.8 & 0.00 & 1.00 & 0 & 0.0 & 1 & 1.9 & -1.01 & 0.31 \\
\hline \multirow{4}{*}{24 months } & C & 9 & 17.0 & 39 & 73.6 & -7.12 & $0.00^{* *}$ & 30 & 56.6 & 42 & 79.2 & -2.57 & $0.01^{*}$ \\
\hline & $\mathrm{P}$ & 15 & 28.3 & 3 & 5.7 & 3.26 & $0.001^{*}$ & 9 & 17.0 & 3 & 5.7 & 1.87 & 0.06 \\
\hline & M & 27 & 50.9 & 9 & 17.0 & 3.95 & $0.00^{*}$ & 14 & 26.4 & 7 & 13.2 & 1.73 & 0.08 \\
\hline & $D$ & 2 & 3.8 & 2 & 3.8 & 0.00 & 1.00 & 0 & 0.0 & 1 & 1.9 & -1.01 & 0.31 \\
\hline
\end{tabular}

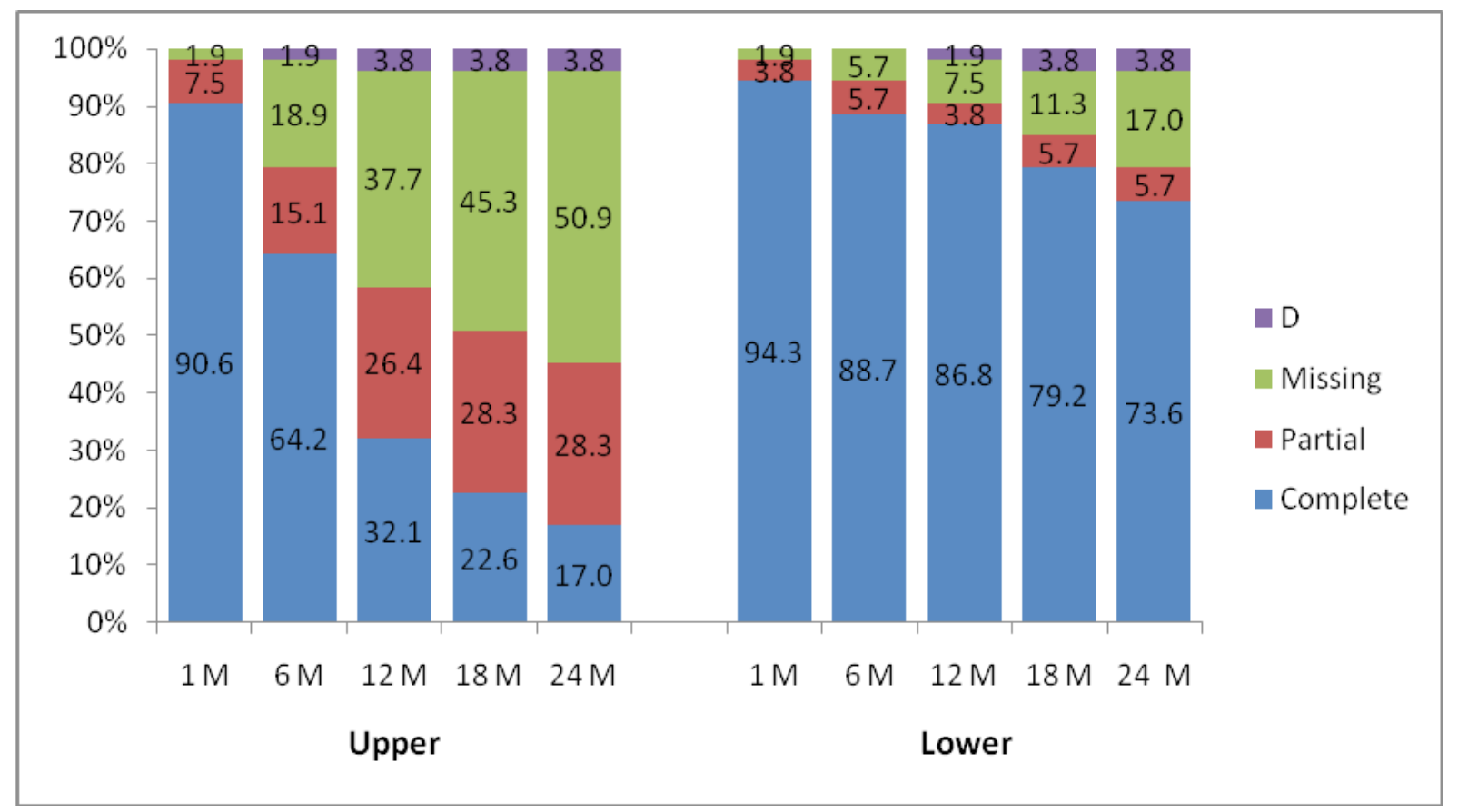

Figure 2: Comparison of sealant retention on upper and lower first permanent molars 
with hydrophilic in nature for the first time with special features which include ${ }^{14,15}$ Self priming, Self adhesive, Less technique sensitive ${ }^{11}$ with Resin Acid - Integrated Network [R.A.I.N.] an improved hydrophilic resin technology, margin free and hydro-balanced, Continuous fluoride release, Water activated and $\mathrm{pH}$ controlled, Water miscible and protects tooth from micro leakage. ${ }^{9-11}$ The bonding to the tooth structure is chemical as well as micromechanical in nature. It is also Bisphenol A (BPA) free i.e. Bis-GMA is absent in Group-II, which according to Amir Azarpazhooh, Patricia A. Main $(2008)^{16}$ has the potential to bind with the estrogen receptors at sub toxic concentrations leading to hazardous outcome. In vitro, found to cause the impairment in the development, health and reproductive systems.

In this study only the teeth, within 4 years of their respective eruption were included, as in a systematic review Azarpazhooh A and Patricia A. Main $(2008)^{17}$ reported that placing sealants within 4 years after eruption seems to be beneficiary. And, the highest risk of occlusal caries is believed to exist in early years of eruption since they have a porous enamel lining and the fissures are rich in cellular and organic debris. The porous zone of enamel bordering the fissures offers a three- dimensional 'honey combed' structure into which fissures sealants should be locked so that the risk of caries is lower and the consequence of loss of sealants would be less important. ${ }^{14,18}$

In this study a thorough prophylaxis of the teeth was first performed, using a rotatory brush and pumice. ${ }^{19}$ pumice prophylaxis prior to etching reduces micro leakage thereby improving the retention of the sealant. Isolation was done using Cotton rolls as stated that absolute isolation is not necessary for the application of sealants as long as extreme care is taken to avoid salivary contamination of the etched surface. ${ }^{14,20}$ As resins do not form hydrolytically stable bonds their retention on tooth structure is based on the durability of the mechanical bond. ${ }^{21,22}$ Accordingly etching was done for $15 \mathrm{sec}$ with $37 \%$ ortho phosphoric acid following the manufacturer's instructions. ${ }^{22,23}$ And the etched surfaces were thoroughly dried for application of Delton FS. Method of application for Group-II sealant varied slightly where etched surfaces were left with glossy appearance. The sealants were then applied immediately in permanent first molars of all the patients as per the manufacturer's instructions by the direct application with their pre-loaded syringes. Curing was done for 20 seconds with the tip of the light held vertical to the sealant surfaces. ${ }^{10,11,14,23,24}$

Clinical evaluation by both visual and tactile examination was carried out to check for the retention of sealant materials at 1, 6, 12,18 and 24 months. The Simonsen's criteria was adopted to evaluate the retention of the sealant. . $^{14,25}$

In the present study, Clinical evaluation at two years has shown complete retention of sealant in seventy-two teeth (67.9\%) of Group II (Embrace Wet Bond) in comparison to 48 teeth $(45.3 \%)$ of Group I (Delton FS). The above observation was found statistically significant $(p=0.001)$. Whereas 36 teeth $(34.0 \%)$ of Group I showed loss of sealant in comparison to 21 teeth $(19.8 \%)$ of Group II which was also statistically significant $(p=0.02)$. Remarkably only one tooth showed secondary caries in Group II (Embrace Wet Bond) compared to four teeth in Group I (Delton FS).

These findings are in accordance with studied, ${ }^{11}$ who found Embrace ${ }^{\mathrm{TM}}$ Wet Bond to be superior to Delton FS in sealing ability, fissure penetration and micro leakage. Though Delton FS exhibited higher shear bond strength and lower fracture patterns and micro leakage. ${ }^{26}$ The possible reasons for low retention rate of Delton FS (Group I) can be attributed to its hydrophobic property. Clinical evaluation of sealant retention in upper and lower teeth at two years has shown a total of 30 upper teeth of Group II (Embrace Wet Bond) with complete retention when compared to only nine teeth of Group I (Delton FS). Caries incidence was observed in only one lower tooth of Group II (Embrace Wet Bond) compared to two upper and two lower tooth of Group I (Delton FS). By and large the retention rate of Embrace Wet Bond sealant material in upper teeth is comparatively more than Delton FS sealant.

Additionally this study revealed higher sealant retention rates for the mandibular teeth which could be attributed to the direct visualization making the application more easier and improved without much visual errors, gravity-aided flow of the sealant, and the presence of well-defined pits and fissures in mandibular molars contribute to superior retention. ${ }^{14,27,28}$ The effect of occlusal stress on the sealant of the maxillary molar appeared at an earlier stage of eruption compared with that of the mandibular molar. ${ }^{28}$ The decrease in retention rates found in 8-9-year old children may be related to the occlusal stress that occurs during eruption. In the earlier stages of mandibular eruption, the maxillary teeth contact only mandibular cusps not reaching the sealant. ${ }^{29}$ Dental sealants are a proven tool in caries prevention. ${ }^{30}$ Whether the prevention of caries is due to obturation of the fissures or to the local presence of fluoride, or due to both, In children with high risk of caries, excessive salivation, mentally and physically challenged, very young children, uncooperative child and 
partially erupted molars, the use of Group-II as a fissure sealant should be encouraged rather than the traditional approach of waiting until the tooth fully erupts. The ease of application, reduction in operating time, and the adherence of these materials to moist teeth favour their placement. ${ }^{31}$ These advantages of Group-II sealant make it a suitable sealant for community care programs.

\section{CONCLUSION}

Hence, it can be concluded that hydrophilic (Group-II) sealant may be used as effective pit and fissure sealants especially in children with high risk of caries, excessive salivation, mentally and physically challenged, very young children, uncooperative child and partially erupted molars. The use of Group-II with Resin Acid - Integrated Network [R.A.I.N.] an improved hydrophilic resin technologyas a fissure sealant should be encouraged as the ease of application, reduction in operating time, and the adherence of these materials to moist teeth favours their placement. These advantages of Group-II sealant make it a suitable sealant for community care programs. However, due to the variations in techniques of both hydrophilic and hydrophobic sealants available, they should be tested and observed for over longer periods in future.

\section{CONFLICT OF INTEREST}

Authors declared there is no conflict of interest.

\section{ACKNOWLEDGEMENTS}

The authors would like to thank all faculty members for their valuable guidance and all the patients and their parents for their cooperation during this follow-up study.

\section{Highlights of Paper}

- This present study is the first in vivo study done comparing the retention Of Hydrophobic and Hydrophilic Pit and Fissure Sealant for two long years with split mouth technique.

- This present study apprises us with hydrophilic (Group-II) sealant a Resin Acid-Integrated Network [R.A.I.N.] technology, which can be suitable for community care programs as a fissure sealant due to its ease of application, reduction in operating time, and the adherence of these materials to moist teeth.

- This study proposes that hydrophilic (Group-II) sealant can be used as effective pit and fissure sealants especially in children with high risk of caries, excessive salivation, mentally and physically challenged, very young children, uncooperative child and partially erupted molars.

\section{Author Profile}

- Dr. A.Ratnaditya is an Assistant Professor in Vishnu Dental college from past three years. Main fields of focus are meeting the dental treatment needs of children sensibly with pharmacological and non pharmacological behaviour modification. Also entrusted in Special child care \& management. Passionate towards Research activities in improving Infant and child oral health care. Enthusiastic in partiscipation of Knowledge upgrading Activities like CDE Programs, Academic Reviews \& Conferences.

\section{REFERENCES}

1. Pinkham Casamassimo Fields, McTigue Nowak. Pedriatic dentistry, Infancy through Adolescence. $4^{\text {th }}$ ed. Elsevier Publishers; 2005. 521-22.

2. Richard Mathewson J, Robert Primosch E. Fundamentals of Pediatric Dentistry. $3^{\text {rd }}$ ed. Quintessence Publishing Co; 2008. 119-20.

3. Shobha Tandon. Textbook of Pedodontics $2^{\text {nd }}$ ed. Paras Medical Publishers; 2008. 257-58.

4. James Selectman B, Barry Owens M, William Johnson W. Effect of preparation technique, fissure morphology, and material characteristics on the In Vitro margin permeability and penetrability of pit and fissure sealants. Pediatr Dent. 2007; 29(4): 308-14.

5. Simonsen RJ. Retention and effectiveness of a single application of white sealant after 10 years. J Am Dent Assoc. 1987; 115(1): 31-6.

6. Simonsen RJ. Retention and effectiveness of dental sealant after 15 years. J Am Dent Assoc. 1991; 122(10): 34.

7. Simonsen RJ. Pit and fissure sealant: review of the literature. Pediatr Dent. 2002; 24(5): 393-414.
8. Strassler HE, Grebosky M, Porter J, et al. Success with pit and fissure sealants. Dent Today 2005; 24(5): 124-40.

9. Howard Strassler E, Joseph O'Donnell P. A Unique MoistureTolerant, Resin-Based Pit-and-Fissure Sealant: Clinical Technique and Research Results. Inside Dentistry. 2008; 4(9): 108-10. Available in: http://www.dentalaegis.com/id/2008/10/a-uniquemoisture-tolerant-resin-based-pit-and-fissure-sealant-clinicaltechnique-and-research-results [Last accessed on 31/01/2014].

10. Joseph O Donnell P. In vivo evaluation of Embrace ${ }^{\mathrm{TM}}$ Wetbond ${ }^{\mathrm{TM}}$ Pit And Fissure Sealant ; Internal Report 2003.www.linkedin.com/ pub/joseph-o-donnell/18/7A6/449

11. Wladimir Aranda, Frederic Courson, Michel Degrange. In vitro Evaluation of Embrace TM Wetbond TM pit and fissure sealant. European Cells and Materials 2005; 9(Suppl 1): 73-4.

12. Michael Buonocore G. A simple method of increasing the adhesion of acrylic filling material to enamel surfaces. J. Dent. Res. 1955; 34(6): 849-53.

13. Ana Karina Mascarenhas, Huda Nazar, Sabiha Al-Mutawaa, 
Pramod soparkar effectiveness of primer and bond in sealant retention and caries prevention. Pediatric Dentistry 2008; 30(1): 25-8.

14. Subramanium P, Konde S, Mandanna DK. Retention of a Resin Based Sealant and a Glass lonomer used as a Fissure Sealant - A comparative clinical study. J Indian Soc pedod Prevent Dent. 2008; 14(3): 119-24.

15. Jane AW. Pit and fissure sealants in High-Caries-Risk Individuals. Journal of Dental Education 2001; 65(10): 1084-90.

16. Azarpazhooh A1, Main PA. Is there a risk of harm or toxicity in the placement of pit and fissure sealant materials? A systematic review. J Can Dent Assoc. 2008; 74(2): 179-83.

17. Azarpazhooh A, Main PA. Pit and fissure sealants in the prevention of dental caries in children and adolescents: A systematic review. J Can Dent Assoc. 2008; 74(2): 171-7.

18. Theodore PC. The Quintessence Sealant. Quint Int. 1996; 127(3): 729-32.

19. Ansari K, Oloomi G, Eslami B. Micro leakage assessment of pit and fissure sealant with or without the use of pumice prophylaxis. Int J Pediatr Dent. 2004; 14(4): 272-8.

20. Barbara F, Susan Griffin O. Preventing dental caries through school-based sealant programs- updated recommendations and reviews of evidence. J Can Dent Assoc. 2010; 3(6): 9-18.

21. Poulsen $S$, Laurberg $L$, Jensen $U$. A field trail of resin based and glass-ionomer fissure sealants: clinical and radiolographic assessment of caries. Community Dent Oral Epidemiol. 2006; 34(1): 36-40.

22. Duggal MS, Tahmassebi JF, Toumba KJ, Mavromati C. The effect of different etching times on the retention of fissure sealants in second primary and first permanent molars. Int J Paediatr Dent. 1997; 7(2): 81-6.

23. Robert Feigal J. The use of pit and fissure sealants. Pediatric dentistry. 2002; 24(5): 393-45.

24. Caio Zanet G, Victor, Arana-Chavez E, Marcelo Fava. Scanning electron microscopy evaluation of the effect of etching agents on human enamel surface. J Clin Pediatr Dent. 2006; 30(3): 247-50.

25. Simonsen RJ. Pit and Fissure Sealant: Review of literature. Pediatric dentistry 2002; 24(5): 415-5.

26. Kitae Park, Maria Georgescu, Warren Scherer, Alan Schulman. Comparison of shearstrength, fracture patterns, and microleakage among filled, filled, and fluoride-releasing sealants. Pediatric Dentistry. 1993; 15(6): 418-21.

27. Aranda M, Garcia-Godoy F. clinical evaluation of the retention and wear of a light cured pit and fissure sealant. J Clin Pediatr Dent. 1996; 19(4): 273-7.

28. Zideddin Sheykholeslam, Michael Buonocore G. Bonding of Resins to Phosphoric Acid-Etched Enamel Surfaces of Permanent and Deciduous Teeth. J Dent Res. 1972; 51(6): 1572-6.

29. Erik Asmussen Penetration of restorative resins into acid etched enamel. II: Dissolution of entrapped air in restorative resin monomers. Acta Odontol Scand. 1977; 35(4): 183-9.

30. Muller-Bolla M, Lupi,Pugurier L, Tardieu C, Velly AM. Automarchi Retention of resin sealant, a systemic review. Community Den Epidemiol 2006; 34(5): 321-6.

31. Avinassh J, Marya CM, Dingra S, Gupta P. Pit and Fissure Sealant: An Unused Caries Prevention Tool. JOHCD. 2010; 45(2): 1-6. 